\title{
Anterior cervical plating
}

\author{
V. Gonugunta, A. A. Krishnaney, E. C. Benzel*
}

Department of Neurosurgery, The Cleveland Clinic Foundation and ${ }^{*}$ Cleveland Clinic Spine Institute, The Cleveland Clinic Foundation 9500, Euclid Avenue S80, Cleveland, $\mathrm{OH}-44195$, USA

\begin{abstract}
Although anterior cervical instrumentation was initially used in cervical trauma, because of obvious benefits, indications for its use have been expanded over time to degenerative cases as well as tumor and infection of the cervical spine. Along with a threefold increase in incidence of cervical fusion surgery, implant designs have evolved over the last three decades. Observation of graft subsidence and phenomenon of stress shielding led to the development of the new generation dynamic anterior cervical plating systems. Anterior cervical plating does not conclusively improve clinical outcome of the patients, but certainly enhances the efficacy of autograft and allograft fusion and lessens the rate of pseudoarthrosis and kyphosis after multilevel discectomy and fusions. A review of biomechanics, surgical technique, indications, complications and results of various anterior cervical plating systems is presented here to enable clinicians to select the appropriate construct design.
\end{abstract}

Key Words: Anterior cervical plating, spinal instrumentation, biomechanics

\section{Historical perspective}

Early spinal arthrodeses were performed as stand-alone structural grafts and required prolonged bedrest or cast immobilization. Early reports of cervical arthrodesis were published by Cloward, ${ }^{[1]}$ Smith and Robertson ${ }^{[2]}$ and others, and involved noninstrumented cervical spine arthrodesis with a high nonunion rate. Bohler in 1967 first reported what was likely the first use of anterior cervical plate and screw fixation in a patient with cervical spinal trauma. ${ }^{[3]}$ Although anterior cervical instrumentation was initially used in cervical trauma, because of obvious benefits of this instrumentation, indications for its use have been expanded over time to degenerative cases, including patients with multilevel decompressions, those with allograft use, and those who smoke, as well as cases of tumor and infection. Hence, there has been a progressive increase in the number of surgeries with anterior cervical arthrodesis and plating. Abraham and Herkowitz ${ }^{[4]}$ noted a three fold increase in the incidence of cervical fusion surgery between 1985 (38,000 cases) and 1996 (1,10,000 cases) in the USA based on the Health Care Finance Research Society. Along with increased use of plating systems, implant designs evolved over the last three decades. Orozco and Houet ${ }^{[5]}$ described the use of a one-third tubular plate in 1970s and subsequently designed custom ' $\mathrm{H}$ ' and 'HH' plates that were adopted by the Arbeitsgemeinschaft fur Osteosynthesefragen (AO) for use throughout Europe in anterior cervical spine surgery. Caspar ${ }^{[6]}$ developed a 'trapezoidal' plate in 1980 for use in cervical spine and he described later the use of this plate for multiple indications including trauma, tumors, revision surgery etc. Early devices required penetration of posterior cortex of vertebral body (bicortical purchase) and the fear of dural penetration and subsequent neurologic catastrophe delayed acceptance of the use of these devices worldwide, particularly in the United States. The most popular, second generation systems (e.g., CSLP from Synthes, Orion from Sofamor-Danek, Codman plate) featured screws fixed to the implant and permitted screw convergence on placement. The latest, third generation systems are the dynamic semi-constrained plates to prevent stress shielding and to allow subsidence, described below.

\section{Biomechanics of anterior cervical spine plating}

A basic understanding of the complex biomechanies of ventral cervical plating is necessary to help selecting the right construct. The forces acting on the plate (and the subaxial cervical spine) are highly variable and dependent on a number of factors including, length and design of the construct, position of the spine (flexion $v$ s extension), and plate and screw design.

Constrained plates: The most basic anterior cervical plates 
(ACP) have screws rigidly affixed to the plate (constrained) and act as fixed moment arm cantilever beams providing ventral distraction fixation with the spine in neutral position. Usually this mode of application is intended at the time of surgery with active distraction of the vertebral bodies and placement of an interbody graft. When placed in a neutral construct at the time of surgery, the subsequent axial load borne by the implant effectively distracts the spine by resisting compression. In extension, these plates resist distraction at the ventral aspect of the vertebral body thereby functioning as a tension-band. ${ }^{[7]}$ Flexion forces are not effectively resisted by screw - plate constructs potentially resulting in screw cutout or plate bending. The presence of dorsal spinal stability to act as a limiter of flexion deformation can reduce the risk of these potential complications. ${ }^{[7]}$

Semi-constrained plates: Two concepts, subsidence and stress shielding are important to understand the development of semiconstrained plates.

Subsidence: Subsidence or settling refers to loss of height at the operative site following surgery on the spine, and this is caused by (1) bone graft absorption with remodeling, (2) graft collapse, and (3) pistoning of the graft. Graft remodeling and resorption is a normal and complex biological process during bone healing, involving various inflammatory mediators, humoral, and growth factors and mechanical forces. As a result, bone graft first partially resorbs before being replaced by new living bone. This process leads to subsidence of the bone graft and it should be emphasized that this is not a pathological process. The amount of subsidence depends on type of grafting and the number of levels fused. The average settling in Bishop's series for single and two level iliac crest autograft constructs was 1.4 and $1.8 \mathrm{~mm}$, respectively, compared to 2.4 and $3.0 \mathrm{~mm}$ for single and two level iliac crest allograft constructs respectively. ${ }^{[8]}$ Graft collapse occurs prior to its incorporation, again leading to subsidence.

Stress shielding: There should be an optimal amount of load sharing between the spinal implant and the bone graft. It has been reported that $70 \%$ of the load should be transmitted through the spine (not the implant) to optimally enhance both arthrodesis and acute stability. ${ }^{[9]}$ Bone heals best under compression via the augmentation of the bone healing enhancing forces (Wolfe's law). Stress shielding is defined as 'an implant induced reduction of bone healing, enhancing stresses and loads to such a degree that stress reduction osteoporosis, or nonunion, may result.' However, compressive forces in the case of an interbody fusion with an accompanying stress shielding implant are not allowed to be transmitted to the graft-vertebral body fusion surfaces, resulting in nonunion or pseudoarthrosis (Figures 1 and 2). It is well known that in some situations, failure of an implant (for example by a fracture) permitted the bone grafts to 'see' bone-healing forces, thus encouraging fusion (Figure 3). If the plate had not failed in these cases, pseudoarthroses may have developed. This concept is referred to as secondary dynamism by plate fracture. Benzel et al. ${ }^{[10]}$ focused attention on the above phenomena of stress shielding and secondary dynamism and used this knowledge to

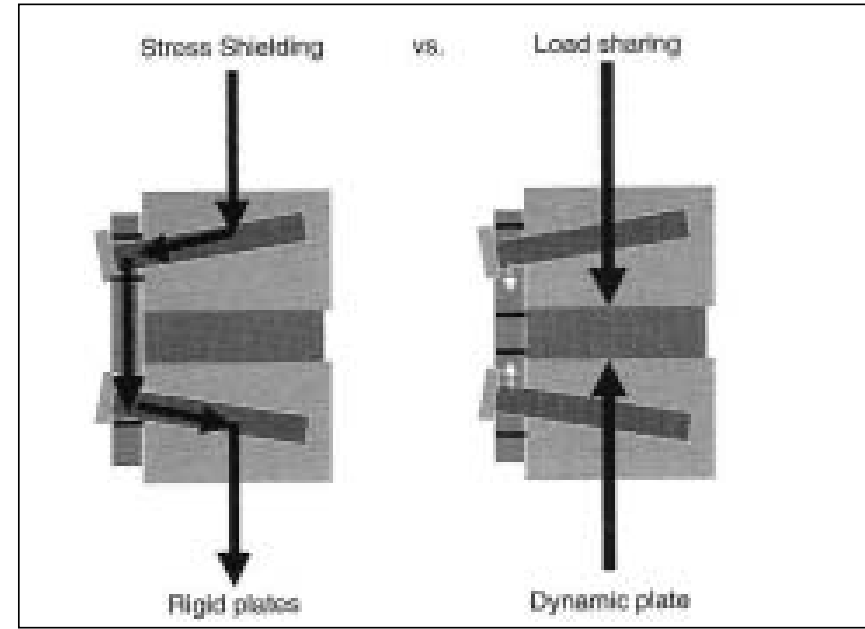

Figure 1: Bold arrows depict the parthway of major axial loading forces. In the rigid system the load is cantilevered around the graft, traveling through the screws and plate-thus shielding the graft.

Dynamic systems transfer most of the axial load to the graft, since the screws are free to slide in the slots in the plate (small arrows). This keeps graft loaded, allowing the principle of Wolff's law to act (With permission from Elsevier Churchill Livingstone, Spine Surgery: Techniques, Complication Avoidance, and Management. Second Edition, Volume II, Editor: Benzel EC, 2005)

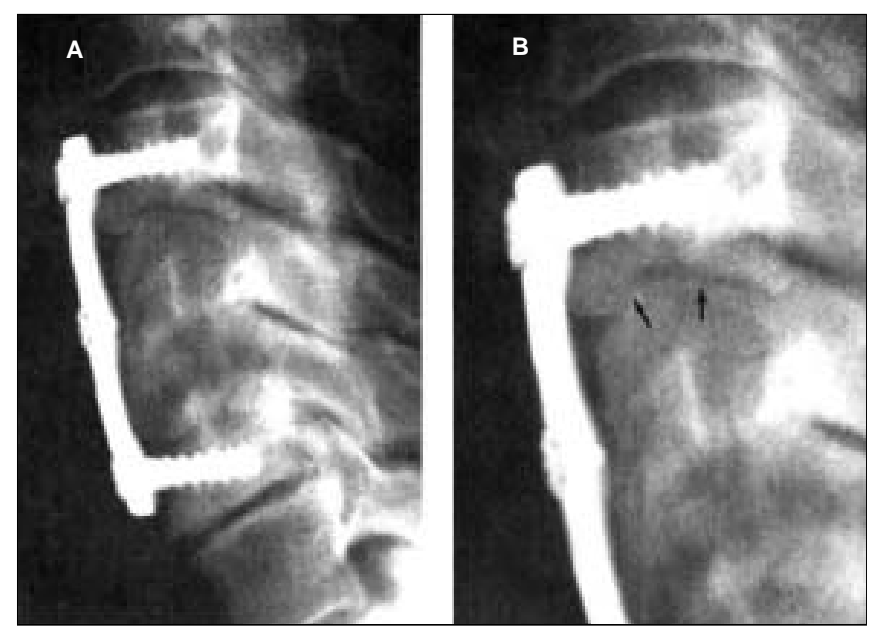

Figure 2: (A) A ventral rigid cervical implant caused stress shielding, which resulted in nonunion (pseudoarthrosis) in a patient with preexisting osteoporosis, as depicted. (B) Arrows outline the location of the nonunion (close up) (With permission from AANS - Biomechanics of Spine Stabilization. Benzel EC, 2001)

develop the first axially dynamic cervical implant.

Dynamic or semiconstrained implants are nonfixed moment arm cantilevers and, in general, function by two mechanisms ${ }^{[7]}$ : screw toggling or permission of axial subsidence. Screw toggling is created by the interface of a rounded screw head with a cup on the plate (Figure 4). Once the screw is placed, the rounded head/cup configuration allows the screw to rotate in the sagittal plane with respect to the plate as subsidence occurs. Although this mechanism allows subsidence the fixed head position of the screws may lead to rotation of the vertebral body as it settles or, more likely, screw cut out $^{[7]}$ (Figure 5). Another form of dynamism is related to the allowance of axial settling. ${ }^{[10]}$ In this configuration the screws are 


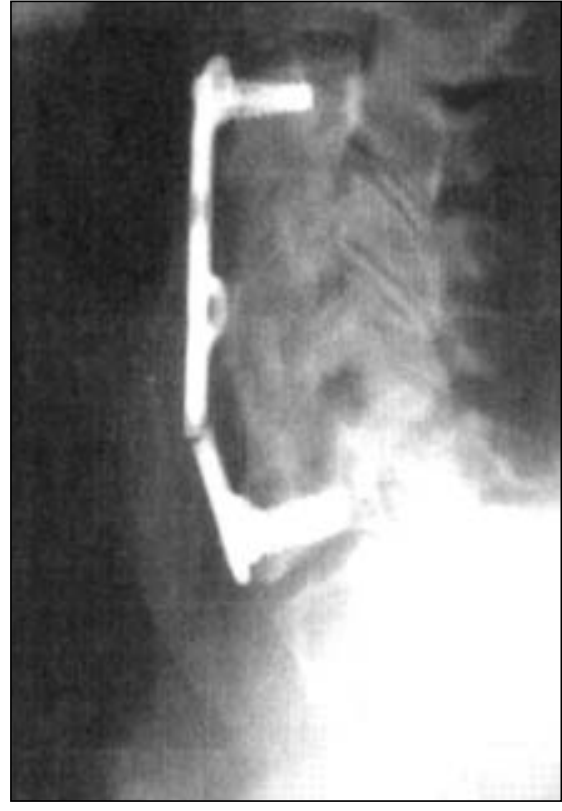

Figure 3: An example of secondary dynamism-plate failure by fracture allowing the bone graft to see bone healing enhancing compressive forces, thus allowing fusion to occur (With permission from AANS Biomechanics of Spine Stabilization. Benzel EC, 2001)

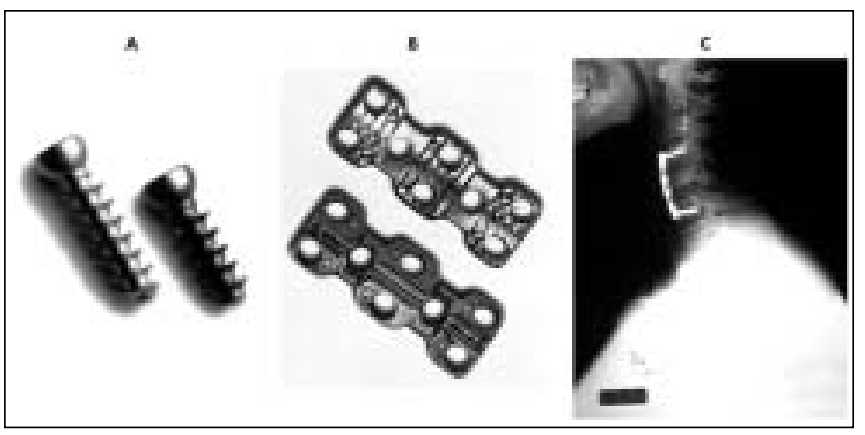

Figure 4: Implants that limit but allow some toggling (Codman plate) provide an intermediate alternative between the fixed and non-fixed moment arm cantilevers. This is facilitated by a round-bottom screw

head that fits into a cup on the plate (A and B). A cam permits 'limited toggling' (C).

allowed to slide along the long axis of the plate for a limited distance. This configuration may allow subsidence while minimizing the risk of screw cutout.

\section{Implant failure}

Implants fail at points of maximal stress. This point may be at the screw-bone interface, within the screw itself, at the screw-plate interface, or within the plate. Failure at the screw - bone interface occurs by either screw back-out or screw cut-out. In early anterior cervical constructs screw back-out was combated by obtaining bicortical purchase when placing the screws. More recently, a variety of screw-plate locking mechanisms have minimized the chanced of this mode of failure and obviated the need to obtain bicortical purchase. Screw cut out is a more common form of failure at the screw-bone interface. In this circumstance, subsidence causes the screw to 'windshield wiper' through the bone thereby allowing the

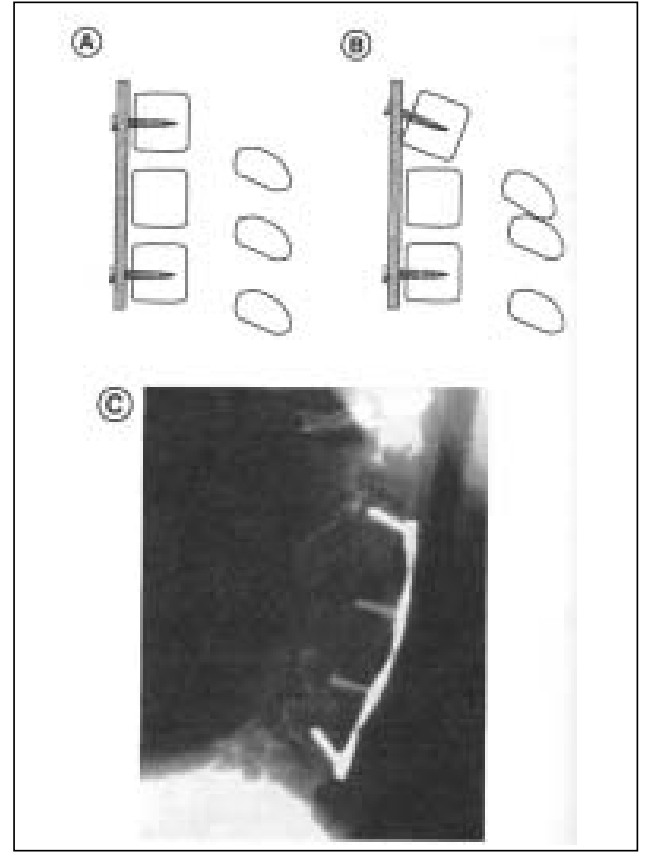

Figure 5: Nonfixed moment arm cantilever beam implants allow screw toggling and thus permit angular deformation ( $A$ and $B$ ). This is not usually considered desirable. A clinical example is shown in lateral $x$ ray (C) (With permission from AANS - Biomechanics of Spine Stabilization. Benzel EC, 2001)

screws to lose purchase and subsequently pull out of the bone. This mode of failure is more commonly seen in nonfixed moment arm cantilever (toggling) type screws. The unique geometry and regional anatomy of the lower cervical spine and the cervicothoracic junction apply additional stress to the caudal screw-bone junction for constructs extending to these levels and often leads to failure. Strategies that can minimize screw pull out include triangulation, providing additional points of fixation, minimizing the length of the construct, and normalizing the geometry of the cervical spine.

Screws break at the point of maximal stress. For fixed inner diameter, fixed moment arm cantilever screws this occurs at the screw plate interface. For tapered screws the point of maximal stress is in mid-shaft. ${ }^{[11]}$

Construct failure occurs where the magnitude of the applied bending moment is maximal and a relative weak point coincide (point of maximal stress). ${ }^{[11]}$ This may occur in any part of the construct (plate, screws, screw-plate interface, and screw-bone interface). The specific part of the construct that fails is related to the direction and magnitude of the forces applied to the implant (either intentionally or unintentionally). Knowledge of the forces applied to the implant at the time of application as well as with position change can help the surgeon to minimize the risk of these potential complications with rational construct design and implant selection.

\section{Indications for anterior cervical fixation}

There are four general indications for spinal stabilization as outlined by White and Panjabi ${ }^{[12]}$ - (1) to restore clinical stability 
to a spine in which the structural integrity has been compromized, (2) to maintain alignment after correction of a deformity, (3) to prevent progression of a deformity, and (4) to alleviate pain. Spinal instrumentation with a bone fusion can be applied in all of these scenarios and in cervical spine surgery, the indications include traumatic or acquired cervical spine instability, cervical vertebrectomies, metastatic lesions of vertebral bodies, cervical fractures, multilevel cervical discectomies, single level cervical discectomies for infection. Rarely, instrumentation may replace bone fusion as the principal means of cervical stabilization. The main benefit of spinal instrumentation is provision of immediate postoperative stability to the surgical zone before the development of osseous fusion.

\section{Surgical technique of ventral cervical plating}

Planning: Several factors, such as, the indication for surgery (traumatic $v s$ degenerative), quality of bone (osteoporosis, osteomyelitis), levels of decompression and levels of fusion, choice of graft (autograft $v$ s allograft, bone graft $v s$ cage), aberrant anatomy, if any on the images, etc. should be reviewed thoroughly and the type of construct to be used should be selected prior to entering the operating room.

Exposure: It need not be overemphasized that adequate exposure is the key to avoid complications of ventral cervical fixation. Generally, access is obtained using a standard transverse skin crease incision, but an incision paralleling the sternocleidomastoid may be preferred when four or more cervical discs are to be exposed. Access to the vertebral body above and below the graft site must be attained to gain access for purchase of the plating system. Exposure of the disc spaces above and below the vertebral body, upon which the fixator is to be attached, is often helpful but not mandatory to avoid placing the screws into the disc space. Instead, intraoperative fluoroscopy can be used to avoid the above risk.

Bone grafting: Poor grafting technique may lead to increased mechanical stress on the plating system and may cause plate or screw failures. The key principles for successful bone grafting include (1) establishment of good bony contact between the graft and the bone, (2) placement of the graft in a compression mode, and (3) the immobilization of the bone-graft junction. Autologous iliac crest is the gold standard bone graft for cervical fusion, but allogenic fibular graft with or without morphogenic matrix may be used instead to avoid donor-site related complication. It is very important that all disc material is removed, and bone is removed from the endplate until punctate hemorrhage from cancellous bone is seen to achieve good incorporation of the graft. Anterior osteophytes are also trimmed for proper seating of the plate. The rostral and caudal edges of the graft site should be made parallel and careful measurement of the disc space height is performed, and the graft is trimmed to size accordingly. A graft of at least $7 \mathrm{~mm}$ in height and $15 \mathrm{~mm}$ in depth is recommended to minimize graft fracture. Care should be taken that there is a $3 \mathrm{~mm}$ safety margin between the graft and the spinal cord and a nerve hook is placed beneath the graft to ensure that the graft does not impinge the cord. A graft that is significantly taller than the height of interspace may lead to over-distraction of disc space and can result in constant interscapular pain and, rarely neurological deficits from neuropraxia. In traditional Smith-Robinson configuration, cortex of the graft is placed ventrally, and in the middle column of spine in reversed Smith-Robinson technique. In the later technique, graft extrusion rate is less, but rate of kyphosis increases. However, when ventral plating system is added, graft extrusion is eliminated and kyphosis lessens, and hence choice of graft technique is less important.

Plate-screw fixation: A variety of plating systems are available in the market for ventral cervical spine fixation, but the basic techniques are as follows: ${ }^{[13]}$

1. Identification of the midline;

2. Removal of ventral osteophytes to allow the plate to lay in contact with the ventral spine;

3. Selection of the proper length and hole positions of the plate;

4. Measurement of screw length, graft depth, and vertebral body depth prior to placement of screws;

5. Selection of screw length to provide maximal unicortical purchase or minimal spinal canal perforation with bicortical purchase;

6. Alignment of the plate in the midline, with screw holes positioned over the vertebral bodies;

7. Placement of screws into the vertebral body, avoiding the disc space and,

8. Proper locking of the screws into the plate.

There are a few variations of screw placement depending on the plating system. The original Caspar trapezoidal plate (Aesculap,CA, USA) and Orozco (Synthes PA, USA) are nonconstrained systems and bicortical purchase of screws is required-hence fluoroscopy and repeated palpation of the drill hole with K-wire are recommended to avoid injury to the spinal cord. One millimeter of screw thread may penetrate dorsal cortex of vertebra without damaging the cord and this is the approximate thickness of posterior longitudinal ligament. Synthes ventral cervical locking plate (CSLP) system uses screws with unicortical purchase (usually $14 \mathrm{~mm}$ screws) and a locking mechanism to minimize backout of the screws. The rostral screws are angled $12^{\circ}$ upward while the trajectory of the caudal screws is angled perpendicular to the plate. The orion plate, like synthes plate is a constrained system, but has a precontoured lordotic curve. The plate provides a convergent screw pattern, with the screws angling $15^{\circ}$ rostrally and $6^{\circ}$ medially for the rostral holes and $15^{\circ}$ caudally and $6^{\circ}$ medially for the caudal holes. There are currently four axially dynamic ventral cervical plates (Figure 6) commercially available in the United States - the DOC VCSS (Depuyacromed), the ABC plate (Aesculap), the premiere plate (SofamorDanek) and the C-Tec plate (Interpore Cross), each differing in the method of implementation of the principle of dynamic spine stabilization. The DOC VCSS system is not applicable to single level constructs and it consists of platforms rigidly fixed to the vertebral bodies via screws, restricting the toggling of the screws in the vertebral body. Platforms slide along two rods while a cross 


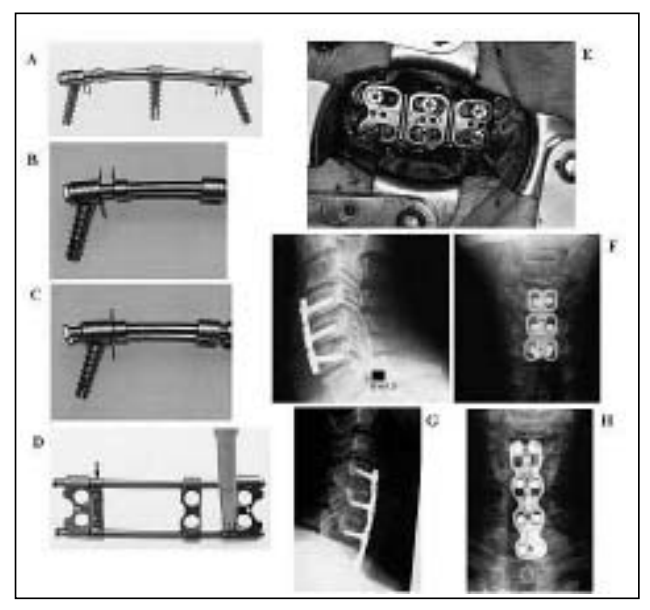

Figure 6: Dynamic implants. DOC system (A-D). Lateral (A), AP (D) views of DOC plate. The amount of subsidence permitted is depicted in $B$ and $C$. $A B C$ system ( $E$ and $F$ ) provides slotted holes to allow axial and angular deformation. Premier plate ( $G$ and $H$ ) provides a graded resistance to subsidence. (With permission from AANS -

Biomechanics of Spine Stabilization. Benzel EC, 2001)

fixator rigidly affixed to the rods limits the amount of sliding, and therefore, the amount of subsidence permitted. On the other hand, the $\mathrm{ABC}$ system has slotted plates to permitting unrestricted subsidence by allowing the screws to slide within the slots. The screws are locked to the plate by internal locking mechanism, which prevents backout but does not restrict either settling or screw rotation. The premiere and C-Tec plates have similar slotted designs to allow settling, with a retaining band over the screw heads to prevent back out.

\section{Complications of ventral plating}

\section{Implant complications}

Coe and Vaccaro in their review of literature, reported that the prevalence of screw and plate loosening was between 0 and $15.4 \%$, the prevalence of screw fracture was between 0 and $13.3 \%$, the prevalence of plate fracture was between 0 and $6.7 \%$, the prevalence of plate and graft displacement (with or without graft fracture) (Figures 7, 8, and 9) was between 0 and 21.4\%, and the prevalence of implant malposition (screws in discs, plating of unfused segments, etc.) was between 0 and $12.5 \% .{ }^{[14]}$ The newer implants are of low profile, designed to minimize the risk of implant dislodgement and to avoid dysphagia/esophageal perforation. Most of modern plates also lock the screws to minimize implant loosening. Lowery and McDonough in their review of 109 patients with three different types of ACP (Orozco, CSLP, and Orion), found overall failure rate of $35 \%$, but combined failure for the locked systems (Orion and CSLP) was only 18\%.[15]

Anterior cervical plating has been used to stabilize long corpectomy constructs with a hope to obviate the need for posterior arthrodesis., but only with mixed results. In a retrospective multicenter study of 45 patients with multilevel corpectomies reported by Vaccaro et al., there was $50 \%$ incidence of graft/plate dislodgement in the three level corpectomies $v s$ only $9 \%$ incidence in two level corpectomies (CSLP system used in all but one, with

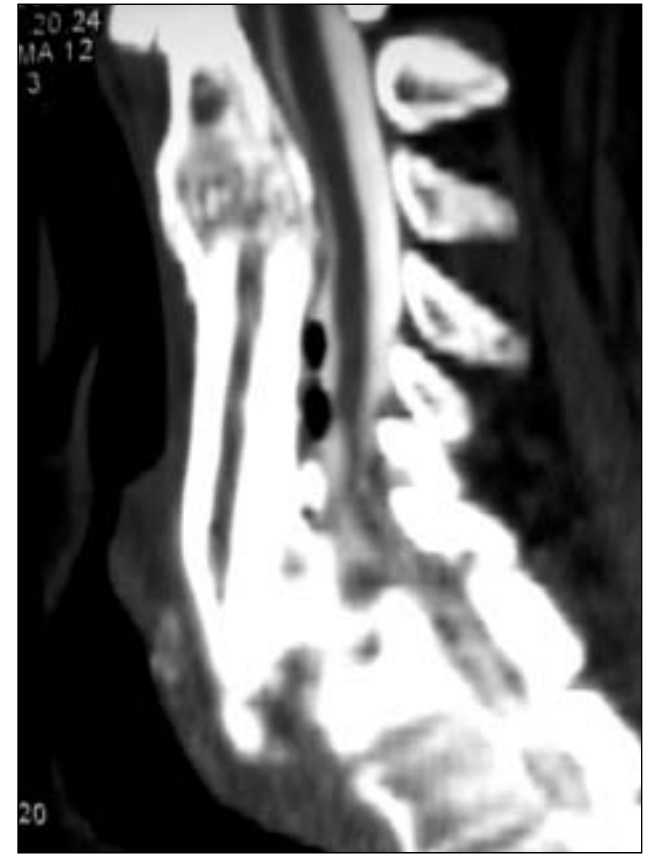

Figure 7: CT of cervical spine demonstrating ventral displacement of strut graft at the caudal end, causing dysphagia

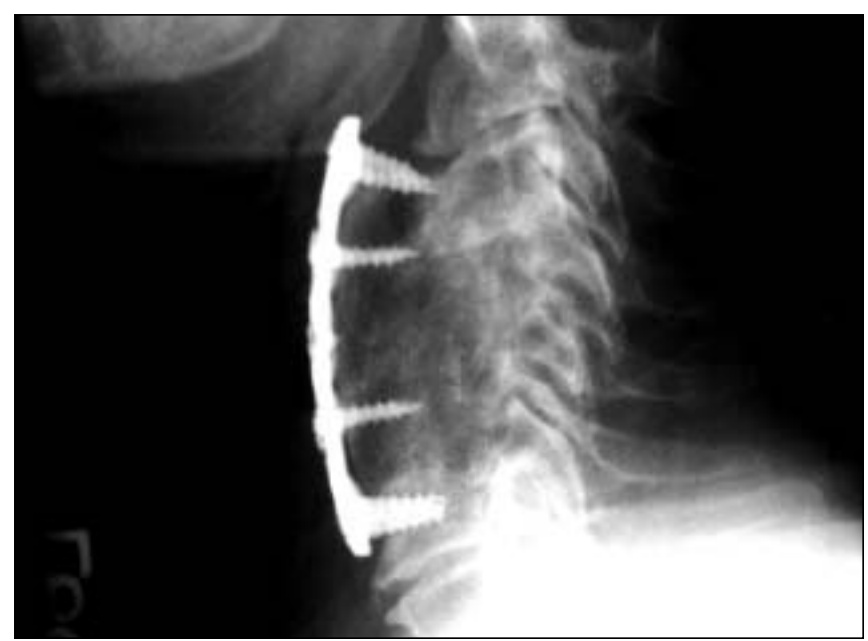

Figure 8: Lateral cervical spine X-ray showing plate and screw kick out

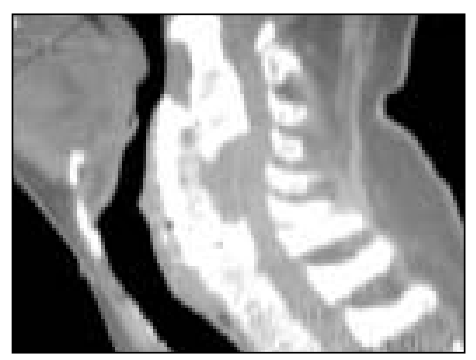

Figure 9: Sagittal CT scan of cervical spine showing plate and graft dislodgement

overall incidence of $20 \%$ in the whole group. ${ }^{[16]}$ Schultz et al. in their series of 72 patients with anterior plate stabilization combined with posterior lateral mass plating had only one anterior plate related complication. ${ }^{[17]}$ Several other studies suggest a decreased 
prevalence of anterior fixation complications in patients who also undergo posterior stabilizations. ${ }^{[18,19]}$

\section{Other complications of anterior cervical plating}

Dysphagia: After ventral cervical surgery may be as high as $60 \%{ }^{[20]}$ higher rates of dysphagia are seen with revision surgery with an increased number of levels arthrodesed. ${ }^{[21]}$ Esophageal injuries (Figure 10) are rare, but are dreaded complications. Injury can occur intraoperatively from a power drill and retractors or postoperatively from extrusion of a bone graft, loosened screws or plates. Oral extrusion of a locking screw from a CSLP ${ }^{[22]}$ and a missing anterior cervical plate and screws presumably passing without notice through the gastrointestinal tract, ${ }^{[23]}$ have been reported. Onset of symptoms may vary between 4 and 360 days and intraoperative injury may go unrecognized. Clinically, the symptoms of esophageal perforation include odynophagia, increasing neck pain, swelling, induration, crepitus, and even sepsis.

\section{Neurological complications}

Injury to the recurrent laryngeal nerve: Is considered the most common neurological complication after anterior cervical spine surgery. The incidence varies between 0.2 and $11 \% .^{[24]-[26]}$ Clinical manifestations range from mild symptoms of hoarseness and loss of effective cough mechanism, to upper pharyngeal dysphagia with aspiration, to life-threatening airway obstruction from bilateral recurrent laryngeal nerve injury. ${ }^{[27]}$ Self-retaining retractors that are too deep, exerting pressure on the trachea and tracheoesophageal groove can result in direct recurrent laryngeal nerve injury. ${ }^{[24,25,28]}$ The injury may be more common on rightsided approaches where the recurrent laryngeal nerve is more variable, ${ }^{[27,29,30]}$ but some reports showed no association. ${ }^{[31]}$ The injury may be more common in the cases of revision surgery. ${ }^{[31]}$ Most commonly the injury to the nerve is transient lasting several weeks, but it may also be permanent. Monitoring of the endotracheal cuff pressure and temporarily deflating the cuff after retractor placement may minimize the injury to the nerve. ${ }^{[32,33]}$ Intermittent relaxation of the retractors may also prevent the injury.

Horner's syndrome (ptosis, pupillary miosis and facial

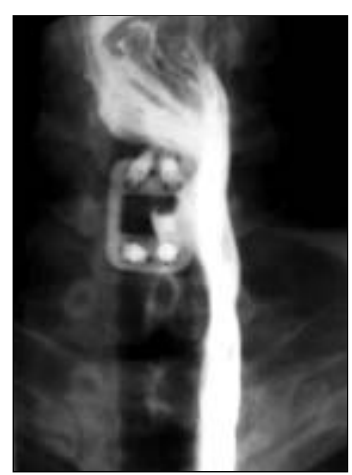

Figure 10: Barium esophagogram showing contrast extravasation following anterior cervical plating and esophageal injury anhidrosis) may occur from injury to the cervical sympathetic chain. The sympathetic trunk is more frequently damaged during the anterior approach to lower cervical spine because it is situated closer to the medial border of the longus colli muscle at $\mathrm{C} 6$ than at C3. The longus colli muscles diverge laterally, whereas the sympathetic trunks converge medially at C6. ${ }^{[34,35]}$ Since the sympathetic plexus lies within the longus colli muscles, it is necessary to keep the dissection medial to this muscle.

Injury to the spinal cord: During ventral approach to the cervical spine is a rare but potentially devastating complication. ${ }^{[36]}$ Spinal cord injury may occur during patient positioning, decompression, fusion, instrumentation, or closure. Extreme flexion and extension of the neck should be avoided. Flexion may induce compression against ventral spondylotic bars. ${ }^{[37-39]}$ This problem is worse with cervical kyphosis. ${ }^{[39]}$ Extension may result in compression of the spinal cord dorsally by the buckling ligamentum flavum. ${ }^{[38,40]}$ One might consider an awake intubation in this situation.

In anterior cervical discectomy and fusion (ACDF), flynn reported an incidence of $0.05 \%$ of postoperative spinal cord injury. ${ }^{[41]}$ Spinal cord trauma can occur during inadvertent slippage of an instrument (a burr, curette or a Kerrison). Large Kerrison rongeurs should not be used, as their footplates may cause spinal cord compression. It is preferred to use a high-speed burr to create a thin shell of bone and to use a microcurette and the operative microscope in order to perform a safe and effective decompression. The placement of a bone graft is a potential of trauma to the spinal cord. The depth of the bone graft should be less than that of the vertebral body. Myelopathy can result from a posterior extrusion of the graft while tracheal obstruction, dysphagia, neurologic injury and kyphosis can result from an anterior extrusion (Figure 2). The incidence of graft extrusion is between 1 and 13\%. Good surgical technique and instrumentation can prevent it. ${ }^{[42]}$ Placement of the screws can cause direct spinal cord injury. This occurs more often with bicortical purchase. Attention to screw and drill length, as well as using drill stops, that limits the depth of the drilling, are important measures while using unicortical fixation in order to avoid inadvertent spinal cord trauma.

The incidence of nerve root palsy has been estimated to be $0.17 \% .^{[43]}$ Ventral decompressive procedures have reported rates of C5-C6 radiculopathy from 2 to $15 \%{ }^{[44]}$ The majority of cases are likely due to nerve root tethering and traction after acute anatomic shift of the spinal cord following decompression from either a ventral or a dorsal approach. The susceptibility of the C5 rootlet to postoperative dysfunction may be due to its anatomic characteristies including shortest length and the most obtuse take off angle from the cord of any cervical root. ${ }^{[45]}$ Saunders identified risk factors associated with the occurrence of postoperative radiculopathy and they include: age greater than 60 years, severity of the preoperative myelopathy, increased number of levels decompressed and the degree of cervical kyphosis. ${ }^{[46]}$ He also found that decreasing the width of the corpectomy defect from 20 to $15 \mathrm{~mm}$ led to a decrease in the occurrence of radiculopathy. Cerebrospinal fluid leak is also a rare complication and if noticed 
intraoperatively, primary repair if possible or fibrin glue sealing if not, should be performed. Lumbar subarachnoid diversion drainage is often helpful in preventing further leak or if leak is recognized postoperatively.

Vascular injuries: Can occur during ventral approaches to the cervical spine. The carotid artery may be torn during exposure and may be occluded due to excessive retraction, which may lead to dislodgement of a plaque with subsequent intracranial embolus. ${ }^{[36,47]}$ To avoid this type of injury, it is important to identify the artery before placing the retractor. The blades of the retractor must be placed under the longus colli muscles after elevating them from their medial side. The proper use of sharp-toothed retractor blades will prevent retraction injuries. Vertebral artery injury can occur if the dissection is taken too far laterally. ${ }^{[48,49]}$ The reported incidence ranges from 0.3 to $0.5 \%$ of cases. ${ }^{[48,49]}$ It has been attributed to direct trauma by instruments and high-speed drills during the extended lateral decompression. Therefore it is important to pay attention when using instruments laterally for the resection of the uncovertebral joint or for performing a foraminotomy. ${ }^{[50,51]}$ This complication can be avoided by identifying the midline and landmarks such as the uncovertebral joints and the longus colli muscles prior to the decompression. ${ }^{[49]}$

Fortunately, infection after cervical spine fusion is uncommon, with a prevalence ranging from 0 to $4.5 \% .{ }^{[52]}$ Wound debridement and parenteral antibiotics effectively treat these infections, but implant removal may rarely be necessary in resistant cases.

\section{Clinical results with anterior cervical plating}

Although there are no randomized, double blinded controlled clinical trials with sufficient enrollment exist regarding ventral subaxial cervical instrumentation to make definitive statements about the use of fixation, the available studies indicate the following:

1. Anterior cervical plating does not conclusively improve clinical outcome of the patients.

2. Plating does not increase complications.

3. Plating does lessen graft extrusion rates.

4. The greater the number of levels fused, the higher the pseudoarthrosis rate.

5. Plate fixation appears to lessen the rate of pseudoarthrosis and kyphosis.

Anterior cervical plate fixation has gained widespread acceptance for the treatment of various cervical spine pathologies as theoretically, it enhances the rate of arthrodesis (fusion). Several clinical studies support this theory. Kaiser et al. reported the fusion rates for one and two level ACDF with anterior fixation were 96 and $91 \%$, respectively, compared with 90 and $72 \%$ for one and two level ACDF without anterior fixation $(P<0.01) .^{[53]}$ Similarly, in their series of 59 patients who underwent three level discectomy with and without plate fixation, Wang et al. found that the pseudoarthrosis rate was $18 \%$ for patients with plating and $37 \%$ for patients with no plating. ${ }^{[54]}$

As mentioned before, several dynamic implants (third generation implants) are introduced into the market, to eliminate the symptoms associated with previous generation implants and early results of these systems are now available. Apfelbaum et al. ${ }^{[55]}$ reviewed nearly 500 patients involving 800 motion segments with the ABC plating system and reported effective stabilization of the spine in cases of both autograft and allograft fusion, and interbody and corpectomy approaches. Fusion rate was $67 \%$ at 3 months and $100 \%$ at 24 months, and preservation of lordosis seen in $95 \%$ cases. Of note, unrestricted settling allowed by ABC dynamic plating did not cause excessive settling, but facilitated earlier and more substantial fusion. Steinmentz et al reported early experience with the DOC VCSS plate in the treatment of 34 patients with multilevel cervical spondylosis. ${ }^{[56]}$ Minimum follow up was 6 months, with an average of 13 months. Fusion rate was $91 \%$ with no instances of graft or implant failure in that early follow up. Khoo et al. ${ }^{[57]}$ reported a series of 61 patients with cervical spine trauma - and found that ABC dynamic plating system performed substantially better than the rigid and semi-constrained systems, with less settling, better preservation of lordosis and no construct failure. In summary, axially dynamic fixation systems permit subsidence while stabilizing the spine and minimizing the chance of screw, plate or rod fractures, and are emerging as systems of choice for ventral cervical stabilization. However, long-term results are awaited.

Controversy still exists about 'adjacent segment changes' following anterior cervical plating. The overall prevalence of adjacent segment degeneration (radiographic changes seen at levels adjacent to previous spinal fusion procedure) is $25 \%$ and that of adjacent segment disease (development of new clinical symptoms that correspond to radiographic changes adjacent to the level of a previous spinal fusion) is $9 \%{ }^{[58]}$ Hilibrand and Robbins found that anterior cervical fusions performed at more than one level had a significantly lower rate of adjacent segment disease than those preformed at a single level $(12 \%$ vs $18 \%, P<0.01)$. Cervical disc replacement with prosthetic disc implants is hence being tried currently in several centers within the United States, as theoretically, preservation of motion segment by avoiding fusion would prevent adjacent segment disease and the need for further surgery. However, based on the available scientific literature, it is still unclear whether adjacent segment changes are the result of spinal fusion with the iatrogenic production of a rigid motion segment or whether these represent the progression of the natural history of underlying degenerative disease.

\section{Future trends}

As mentioned previously, dynamic ACP appears to show great promise in reducing graft and implant complications, although long term follow up is not available. Similarly, early reports with the use of anterior cervical cages with local bone autograft are encouraging ${ }^{[59]}$ and these may be just as effective as iliac autograft in achieving solid fusion. In the United States, FDA approval for the use of bone morphogenic protein (BMP) in cervical spine surgery is pending. Bone morphogenic protein may be useful and cost effective in selected cases. A variety of cervical disc replacement devices (prosthetic cervical discs) are emerging which may obviate 
the need for fusion and may lessen the incidence of adjacent segment degeneration. This, of course, is yet to be proven.

\section{Conclusion}

Anterior cervical plating is indicated for selected traumatic and nontraumatic cervical pathologies. A good understanding of the biomechanics of the implant and the cervical spine is essential to select the appropriate plating system for anterior cervical spine surgery. Anterior cervical plating certainly enhances the efficacy of autograft or allograft fusion and decreases the pseudoarthroses rates after multilevel discectomy and fusions, but, the benefit of routine addition of a plate after a single level fusion is debatable. The costs of complications of not using a plate (even after a single level discectomy and fusion) can be excessive, and hence, plating for all anterior cervical spinal surgeries is justifiable. However, surgeons should be cautious regarding the use of new and potentially improved technologies, such as dynamic implants and prosthetic cervical disc devices.

\section{References}

1. Cloward R. Treatment of acute fractures and fracture dislocations of the cervical spine by vertebral body fusion. A report of 11 cases. J Neurosurg 1961;18:205209.

2. Robinson R, Smith G. Anterolateral cervical disk removing and interbody fusion for cervical disk syndrome. Bull Johns Hopkins Hosp 1955;96:223-224.

3. Bohler J. Sofort und Fruhbehandlung traumatischer Querschnitt Lahmungen. Z Orthop Ihre Grenzgeb 1967:103(4);512-529.

4. Abraham D, Herkowitz H. Indications and trends in use in cervical spine fusions Orthop Clin North Am 1998;29:731-744

5. Orozco DR, Houet J.Osteosintesis en los traumaticos y degnerativos de la columna veterbral. Traumatol Cirvjia Rehabil 1971;1:45-52.

6. Caspar W, Barbier DD, Klara PM. Anterior cervical fusion and Caspar plate stabilization for cervical trauma. Neurosurgery 1989;25:491-502.

7. Benzel, EC. Biomechanies of Spine Stabilization. American Association of Neurological Surgeons. Rolling Meadows, IL. 2001

8. Bishop RC, Moore KA, Weidner A, Hadley MN: Anterior cervical interbody fusion using autogeneic and allogeneic bone graft substrate: a prospective comparative analysis. J Neurosurg 85(2):206-210,1996.

9. Chen BC, Moore DK, et al. Stress shielding characteristics of three anterior cervical plate systems. Presented at the North American Spine Society $13^{\text {th }}$ Annual Meeting, San Francisco, CA, 1998

10. Benzel EC, Yuan HA, Weidner A, et al: Controlled intervertebral settling in multiple level ventral cervical fusion procedures with a dynamic stabilization implant. The American Academy of Neurologic Surgeons Spine Section Meeting. Rancho Mirage, CA, 1998 .

11. Hollowell JP, Reinartz J, et al. Failure of Synthes anterior cervical fixation device by fracture of Morscher screws: a biomechanical study. .J Spine Disord 7(2): 120-125, 1994

12. White AA, Panjabi MM: Biomechanical considerations in the surgical management of the spine. In White AA, Panjabi MM (eds):Clinical Biomechanics of the Spine, ed 2. Philadelphia, PA, Lippincott-Raven, 1990, pp 511-639

13. Malone DG, Alberstone CD: Ventral subaxial cervical fixation techniques. In Benze EC (ed): Spine Surgery: Techniques, Complication Avoidance, and Management, ed 2. Philadelphia, PA, Elsevier Churchill Livingstone, 2005, pages 1469-1476)

14. Coe.JD, Vaccaro AR: Complications of anterior cervical plating. In Clark CR (editor); Benzel EC, Currier BL, Dormans JP, Dvorak J, Eismont F, Garfin SR, Herkowitz HN, Ullrich CG, Vaccaro AR (section editors): The Cervical Spine (4th Edition). Lippincott, Williams, \& Wilkins, Philadelphia, PA, 2005, (1250 pp)

15. Lowery GL, McDonough RF. The significance of hardware failure in anterior cervical plate fixation. Patients with 2 to 7 vear follow up. Spine 1998;23:181-186.

16. Vacearo AR, Falatyn ST, Scuderi G.J, et al. Early failure of long segment anterior cervical plate fixation. J Spinal Disord 1998:11:410-415.

17. Schultz KD Jr, McLaughlin MR, Haid RW Jr, et al. single stage anterior-posterio decompression and stabilization for complex cervical spine disorders. J Neurosurg 2002;93:214-221

18. McAfee PC, Bohlman HH, Ducker TB, et al. One-stage anterior cervical decompression and posterior stabilization. A study of one hundred patients with a minimum of two years of follow-up. J Bone .Joint Surg Am 1995;77:1791-1800.

19. Epstein NE. The value of anterior cervical plating in preventing vertebral fracture and graft extrusion after multilevel anterior cervical corpectomy with posterior wiring and fusion: indications, results, and complications. J Spinal Disord $2000 ; 13: 9-15$

20. Winslow CP, Winslow T.J, Wax MK. Dysphonia and dysphagia following the anterior approach to the cervical spine. Arch Otolaryngol Head Neck Surg 2001;127:5155 .

21. Bazaz R, Yoo .JU. Incidence of dysphagia following anterior cervical spine surgery Paper presented at the Cervical Spine Research Society $29^{\text {th }}$ annual meeting, NovDec 2001, Monterey,CA.

22. Geyer TE, Foy MA. Oral extrusion of a screw after anterior cervical spine plating. Spine 2001;26:1814-1816

23. Fujibayashi S, Shikata J, Kamiya N, et al. Missing anterior cervical plate and screws. Spine 2000;25:2258-2261

24. Heeneman H. Vocal cord paralysis following approaches to the anterior cervical spine. Laryngoscope. 1973 Jan;83(1):17-21

25. Tew JM .Jr, Mayfield FH. Complications of surgery of the anterior cervical spine. Clin Neurosurg. 1976;23:424-34

26. Bertalanffy H, Eggert HR. Complications of anterior cervical discectomy without fusion in 450 consecutive patients. Acta Neurochir (Wien). 1989;99(1-2):41-50.

27. Netterville JL, Koriwchak MJ, Winkle M, Courey MS, Ossoff RH. Vocal fold paralysis following the anterior approach to the cervical spine. Ann Otol Rhinol Laryngol. $1996 \mathrm{Feb} ; 105(2): 85-91$

28. Bulger RF, Rejowski JE, Beatty RA. Vocal cord paralysis associated with anterior cervical fusion: considerations for prevention and treatment. J Neurosurg. 1985 May;62(5):657-61

29. Weisberg NK, Spengler DM, Netterville JL. Stretch-induced nerve injury as a cause of paralysis secondary to the anterior cervical approach. Otolaryngol Head Neck Surg. 1997 Mar;116(3):317-26.

30. Ebraheim NA, Lu J, Skie M, Heck BE, Yeasting RA. Vulnerability of the recurrent laryngeal nerve in the anterior approach to the lower cervical spine. Spine. 1997 Nov $15 ; 22(22): 2664-7$

31. Beutler W.J, Sweeney CA, Connolly P.J. Recurrent laryngeal nerve injury with anterior cervical spine surgery risk with laterality of surgical approach. Spine.2001 Jun 15;26(12):1337-42

32. Apfelbaum RI, Kriskovich MD, Haller JR. On the incidence, cause, and prevention of recurrent laryngeal nerve palsies during anterior cervical spine surgery. Spine. 2000 Nov 15;25(22):2906-12.

33. Kriskovich MD, Apfelbaum RI, Haller.JR. Vocal fold paralysis after anterior cervical spine surgery: incidence, mechanism, and prevention of injury. Laryngoscope. 2000 Sep;110(9):1467-73.

34. Ebraheim NA, Lu .J, Yang H, Heck BE, Yeasting RA. Vulnerability of the sympathetic trunk during the anterior approach to the lower cervical spine. Spine. 2000 Jul 1;25(13):1603-6.

35. Lu J, Ebraheim NA, Nadim Y, Huntoon M. Anterior approach to the cervical spine: surgical anatomy. Orthopedies. $2000 \mathrm{Aug} ; 23(8): 841-5$.

36. Graham .J.J. Complications of cervical spine surgery. A five-year report on a survey of the membership of the Cervical Spine Research Society by the Morbidity and Mortality Committee. Spine. 1989 Oct;14(10):1046-50.

37. Brieg A, Turnbull I, Hassler O. Effects of mechanical stresses on the spinal cord in cervical spondylosis. J Neurosurg 1966;25:45-56.

38. Hirabayashi K, Bohlman HH. Multilevel cervical spondylosis. Laminoplasty versus anterior decompression. Spine. 1995 Aug 1;20(15):1732-4

39. Verbiest H. Chapter 23. The management of cervical spondylosis. Clin Neurosurg. $1973 ; 20: 262-94$.

40. Ferguson RJL, Caplan LR. Cervical spondylitic myelopathy. Neurol Clin $1985 ; 3: 373-382$.

41. Flynn TB. Neurologic complications of anterior cervical interbody fusion. Spine. 1982 Nov-Dec;7(6):536-9.

42. Brown CA, Eismont F.J. Complications in spinal fusion. Orthop Clin North Am. 1998 Oct;29(4):679-99.

43. Flynn TB. Neurologic complications of anterior cervical interbody fusion. Spine. 1982 Nov-Dec; $7(6): 536-9$

44. O'Thole JE, Olson T.J, Kaiser MG Suroical management of dissociated motor loss following complex cervical spine reconstruction. Spine. $2004 \mathrm{Feb}$ 1;29(3):E56-60.

45. Shinomiya K, Okawa A, Nakao K, Mochida K, Haro H, Sato T, Heima S. Morphology of $\mathrm{C} 5$ ventral nerve rootlets as part of dissociated motor loss of deltoid muscle. Spine. 1994 Nov $15 ; 19(22): 2501-4$

46. Saunders RL. On the pathogenesis of the radiculopathy complicating multilevel corpectomy. Neurosurgery. 1995 Sep;37(3):408-12.

47. Cloward RB. Complications of anterior cervical dise operation and their treatment Surgery. 1971 Feb;69(2):175-82.

48. Golfinos JG, Dickman CA, Zabramski JM, Sonntag VK, Spetzler RF. Repair of vertebral artery injury during anterior cervical decompression. Spine. 1994 Nov $15 ; 19(22): 2552-6$

49. Smith MD, Emery SE, Dudley A, Murray KJ, Leventhal M. Vertebral artery injury during anterior decompression of the cervical spine. A retrospective review of ten patients. J Bone .Joint Surg Br. 1993 Mav;75(3):410-5.

50. de los Reyes RA, Moser FG, Sachs DP, Boehm FH. Direct repair of an extracranial 


\section{Gonugunta et al: Anterior cervical plating}

vertebral artery pseudoaneurysm: case report and review of the literature. Neurosurgery. 1990 Mar;26(3):528-33.

51. Pfeifer BA, Freidberg SR, Jewell ER. Repair of injured vertebral artery in anterior cervical procedures. Spine. 1994 Jul 1;19(13):1471-4.

52. Zeidman SM, Ducker TB, Raycroft J. Trends and complications in cervical spine surgery:1989-1993. J Spinal Disord 1997;10:523-526.

53. Kaiser MG, Haid RW Jr, Subach BR, Barnes B, Rodts GE Jr. Anterior Cervical plating enhances arthrodesis after discectomy and fusion with cortical allograft. Neurosurgery.2002 Fe:50(2)229-236.

54. Wang JC, McDonough PW, Kanim LE, et al: Increased fusion rates with cervical plating for three-level anterior cervical discectomy and fusion. Spine 26(6):643-646.

55. Apfelbaum RI, Dailey AT, Soleau S, Barbera .J: clinical experience with a new loadsharing anterior cervical plate. In Watanabe K (ed): Developments in Neuroscience: Proceedings of the $2^{\text {nd }}$ International Mt.Bandai Symposium for Neuroscience, Spine
Section, Elsevier, 2002, pp 563-580.

56. Steinmentz MP, Warbel A, Whitfield M, Bingaman W: Preliminary experience with the DOC dynamic cervical implant for the treatment of multi-level cervical spondylosis. J Neurosurg (Spine 3) 97:330-336,2002

57. Khoo LT, Kim A, Laich DT, et al. Anterior plating of cervical trauma: the effect of plate design on graft subsidence and the preservation of segmental lordosis. Presented at 2002 American Association of Neurological Surgeons Meeting, Chicago, IL, April 2002.

58. Hilibrand AS, Robbins M. Adjacent segment degeneration and adjacent segment disease: the consequences of spinal fusion? Spine J.2004 Nov-Dec;4(6Suppl):190S$194 \mathrm{~S}$

59. Hacker RJ. A randomized prospective study of an anterior cervical interbody fusion device with a minimum of 2 years of follow up results. J Neurosurg 2000;93(Suppl 2):222-226. Spine. 1989 Oct;14(10):1046-50. 